\title{
Monitoramento da Qualidade Hídrica e Eficiência de Interceptores de Esgoto em Cursos d’Água Urbanos da Bacia Hidrográfica do Córrego Jaboticabal
}

\author{
Mauricio José Borges \\ Depto. Agricultura e Abastecimento/Prefeitura Municipal de Jaboticabal - Depto. Engenharia Rural/Faculdade de Ciências Agrárias e Veterinárias \\ FCAV/UNESP - Campus Jaboticabal - Trav. Herófilo da Silveira, 70 - CEP 14887-254 Jaboticabal, SP - mjborges@fcav.unesp.br
}

João Antonio Galbiatti

Depto. Engenharia Rural/Faculdade de Ciências Agrárias e Veterinárias - FCAV/UNESP - Campus Jaboticabal - Rod. Paulo Donato Castelani, km 5 14884-900 Jaboticabal - SP - galbi@fcav.unesp.br

Antonio Sergio Ferraudo

Depto. Ciências Exatas/Faculdade de Ciências Agrárias e Veterinárias - FCAV/UNESP - Campus Jaboticabal - Rod. Paulo Donato Castelani, km 5 14884-900 Jaboticabal,sP -ferraudo@fcav.unesp.br

Recebido: 06/01 - revisão: 06/02 - aceito: 03/03

\section{RESUMO}

Com o objetivo de avaliar a eficiência de interceptores de esgoto como técnica de despoluição dos córregos Cerradinho e Jaboticabal em área urbana, foram coletadas e analisadas amostras de água desses córregos de forma a caracterizar a intensidade de sua poluição à montante e à jusante da confluência dos mesmos. Da água, mensalmente foram analisados os parâmetros vaz̃ão, temperatura, $p H$, demanda química de oxigênio (DQO), nitrogênio total $\left(N_{\text {total }}\right)$ e fósforo total $\left(P_{\text {tota }}\right)$.

Os resultados da pesquisa permitiram concluir que os córregos Cerradinho e Jaboticabal em área urbana, apresentaram aumento da polvição hídrica das nascentes à foz e que a coleta de esgoto urbano por interceptores, não foi suficiente para despoluir as águas desses córregos, apesar de diminuir a sua intensidade. Recomenda-se o desenvolvimento de um plano integrado de manejo bídrico na bacia bidrográfica do Córrego Jaboticabal, de forma a minimizar ou até eliminar sua contribuição negativa à comunidade local e às águas localizadas à jusante da área urbana.

Palavras-chave: interceptores de esgoto; córrego.

\section{INTRODUÇÃO}

Alterações na quantidade, distribuição e qualidade dos recursos hídricos ameaçam a sobrevivência humana e demais espécies do planeta. Pode-se citar o crescimento demográfico e a expansão das atividades econômicas, seja no meio urbano ou rural, como causas do aumento no consumo e na deterioração desses recursos.

Apesar da água representar $75 \%$ da superfície do nosso planeta, menos de $0,02 \%$ é doce e superficial (Grecco, 1998) e, segundo Pádua (1997), 10\% dos recursos hídricos estão poluídos. Dos municípios brasileiros (Santos, 1993), 6\% efetuavam tratamento dos efluentes urbanos, $35 \%$ possuíam rede coletora de esgoto e quase todo esgoto era lançado "in natura” em corpos d'água ou no solo.

Em diversas regiões do Brasil, pesquisas têm sido desenvolvidas analisando a poluição em cursos d'água localizados próximos de centros urbanos (Fernandes, 1998 e Cavalcanti, 1998). Mais especificamente na região nor- deste do Estado de São Paulo, Amaral (1992), Maia (1998) e Amaral (2000), detectaram a baixa qualidade das fontes hídricas utilizadas para as práticas agropecuárias e consumo humano, encontrando-se geralmente mais impactadas quanto mais próximo à zona urbanizada.

$\mathrm{Na}$ cidade de Jaboticabal-SP, praticamente 100\% da população é atendida por sistemas de rede de abastecimento de água e rede coletora de esgoto (Vitta, 1999). Quando da implantação dessa rede de esgoto, os córregos Cerradinho e Jaboticabal já eram os locais de lançamento do esgoto "in natura". No ano de 1993 teve início a implantação de interceptores desse esgoto nas margens dos córregos em área urbana, concluída em 1996 no Córrego Cerradinho e em julho/1999 no Córrego Jaboticabal.

O objetivo do presente trabalho é avaliar o efeito da implantação de interceptores de esgoto em área urbana, como técnica de despoluição, nos córregos Cerradinho e Jaboticabal, através da quantificação de parâmetros indicadores de qualidade hídrica, visando subsídios para o planejamento ambiental. 


\section{MATERIAL E MÉTODOS}

\section{Caracterização da área experimental}

A área de estudo está inserida na bacia hidrográfica do Córrego Jaboticabal, município de Jaboticabal, região Nordeste do Estado de São Paulo (Figura 1), posição geográfica 21'15'22" latitude sul e 48 $18^{\circ} 58^{\prime \prime}$ longitude WG. A população deste município é de 67.129 habitantes, dos quais 90,3\% residem na cidade (IBGE, 2000).

O município de Jaboticabal apresenta clima "Cwa" (classificação Köeppen), definido como clima mesotérmico de inverno seco, onde a temperatura média do mês mais frio é abaixo de $18^{\circ} \mathrm{C}$ e a do mês mais quente acima de $22^{\circ} \mathrm{C}$.

A formação vegetal primária desse município é do tipo floresta latifoliada tropical. Da área total dos imóveis rurais, $91,7 \%$ é usada com agricultura, 6,3\% são Áreas de Preservação Permanente e apenas 2,0\% são fragmentos florestais. A vegetação atual predominante é a cana-de-açúcar (Valeri e Menezes, 2000).

As unidades de solos predominantes na Bacia Hidrográfica do Córrego Jaboticabal são os Latossolos Vermelhos (LV): à montante da cidade são solos com horizonte A moderado distrófico com textura média relevo plano e suavemente ondulado e à jusante são solos com horizonte A moderado distroférrico e com textura argilosa relevo suave ondulado e plano.

Os córregos Cerradinho e Jaboticabal são perenes, classificados como reto para meandro encaixado, de fluxo normal de água do tipo turbulento corrente. À montante da cidade os córregos recebem influência rural de erosão do solo, prática agrícola, criação de animais, área de lazer e piscicultura. $\mathrm{Na}$ área urbana as maiores influências são de esgoto doméstico, entulhos, escoamento superficial, produtos químicos e animais domésticos.

\section{Parâmetros analisados}

Nesta pesquisa foram analisados os seguintes parâmetros de qualidade hídrica:

- Vazão: o sistema fluvial possui mecanismos como a turbulência e o fluxo não uniforme, que regulam o transporte de materiais e conferem certa unidade ao sistema. O conhecimento da vazão no local de amostragem é essencial no cálculo da autodepuração (Margalef, 1983).

- Temperatura: a maioria das espécies animais e vegetais tem limites quanto a tolerar temperaturas máxima e mínima. A elevação da temperatura aumenta o fitoplâncton e a solubilidade de vários compostos químicos e diminui a solubilidade do oxigênio na água (CETESB, 1995).

- $\mathrm{pH}$ : no ambiente natural, a água tem a concentração de íons $\mathrm{H}^{+}$e $\mathrm{OH}^{-}$fortemente influenciada pela pre-

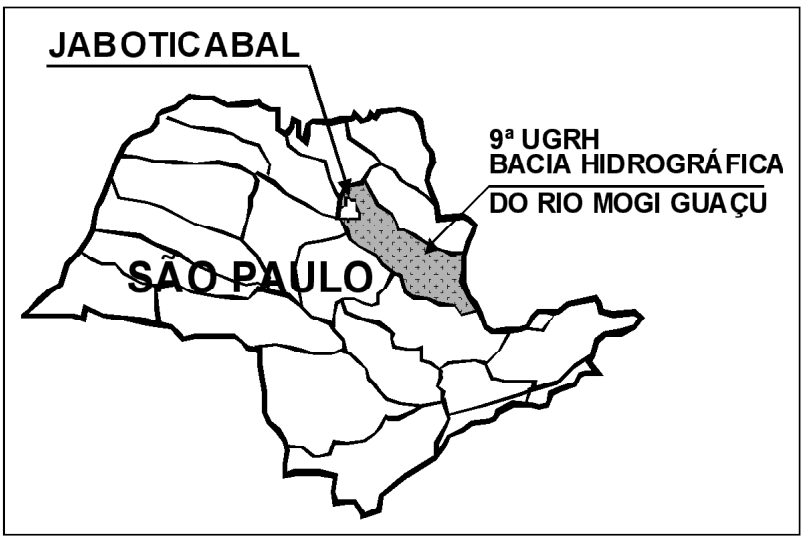

Figura 1. Localização do município de Jaboticabal, SP.

sença de sais, ácidos e bases. O pH fornece indícios sobre a qualidade hídrica o tipo de solo por onde a água percorreu e o tipo de poluição química da água (ácida ou alcalina); em águas superficiais, o valor de $\mathrm{pH}$ varia entre 4 e 9 (Matheus et al.,1995).

- Demanda Química de Oxigênio (DQO): expressa a quantidade de oxigênio requerida para a oxidação da matéria orgânica e inorgânica na amostra de água sobre condições controladas de agentes oxidantes, temperatura e tempo, sem a intervenção de microrganismos. De rápida e simples determinação, a DQO permite medir o teor de matéria orgânica em águas mesmo na presença de despejos que contenham elementos tóxicos (CETESB, 1995).

- Nitrogênio Total $\left(\mathrm{N}_{\text {total }}\right)$ : sugere a presença global de nutrientes em água e o nível de eutrofização da mesma. $\mathrm{Na}$ água, as principais fontes de nitrogênio são o material orgânico de origem alóctone e a fixação de nitrogênio molecular no próprio sistema, podendo ser encontrado nas formas de nitrato, nitrito e amônia, entre outras; sua presença permite a proliferação de organismos, aumentando o consumo de oxigênio (Sipaúba-Tavares, 1998).

- Fósforo Total $\left(\mathrm{P}_{\text {total }}\right)$ : é indicador do grau de eutrofização de um ecossistema aquático. Nas águas naturais o fósforo é encontrado como fosfato, estando normalmente em concentração baixa nas águas superficiais. Esse elemento é essencial à planta, podendo estar dissolvido ou particulado na água, variando sua concentração entre formas associadas orgânicas e inorgânicas oxidadas (Palma-Silva, 1999).

\section{Metodologia}

Quando do início da amostragem em maio/1999, os interceptores de esgoto urbano da cidade de Jaboticabal já estavam em operação no Córrego Cerradinho, enquanto que no Córrego Jaboticabal só foi concluído em julho/1999. 
As estações de amostragem (Tabela 1 e Figura 2) foram definidas em função da implantação dos interceptores, caracterizando: o Córrego Cerradinho, da área rural (C1) até próximo da confluência com o Córrego Jaboticabal (C2); o Córrego Jaboticabal, da nascente (J1) à jusante da confluência com o Córrego Cerradinho (JC1).

Neste estudo, a estação J1 é considerada "branco" para a ação antrópica direta sobre a água pois está em área rural e é o instante em que a água aflora à superfície. As amostras de água foram colhidas mensalmente no período de maio/ 1999 a abril/2000, de quarta a sexta-feira, evitando dias com chuva. As amostras consistiram da água superficial retirada do ponto mais central.

Tabela 1. Localização das estações de amostragem, córregos Cerradinho e Jaboticabal, Jaboticabal, SP.

\begin{tabular}{cccc}
\hline Estação & Córrego & Distância nascente & Localização \\
\hline C1 & Cerradinho & $4,7 \mathrm{~km}$ & Rural \\
C2 & Cerradinho & $10,6 \mathrm{~km}$ & Urbana \\
J1 & Jaboticabal & $0,5 \mathrm{~km}$ & Rural \\
J2 & Jaboticabal & $1,3 \mathrm{~km}$ & Rural/Urbana \\
J3 & Jaboticabal & $4,5 \mathrm{~km}$ & Urbana \\
JC1 & Jabot/Cerra & $5,1 \mathrm{~km}$ & Urbana \\
\hline
\end{tabular}

A temperatura da água foi medida no local da amostragem através da leitura em termômetro de mercúrio. Os demais parâmetros foram analisados em laboratório, sendo o pH através da leitura em potenciômetro digital e a DQO em espectrofotômetro digital HACH DR/2000 (APHA, 1995). Para o $\mathrm{N}_{\text {total }}$ e o $\mathrm{P}_{\text {total }}$, obteve-se extratos da amostra, sendo empregados os métodos titulométrico e colorimétrico proposto por Malavolta et al. (1989), os quais são equivalentes aos descritos no Standard Methods (APHA, 1995).

A vazão foi medida próxima às estações de amostragem, das nascentes à confluência desses córregos. Foi aplicado o procedimento descrito por Azevedo Neto e Alvarez (1982): na estação de menor vazão (J1) foi empregado o processo direto, nas de vazões intermediárias (C1 e J2) foi o de vertedores triangulares e nas de vazões maiores (C2 e J3) foi o do flutuador; a vazão na estação JC1 foi a soma das C2 e J3.

A temperatura do ar e a precipitação pluviométrica (Tabela 2) foram obtidas de um conjunto de dados do acervo da área de Agrometeorologia do Departamento de Ciências Exatas da FCAV/UNESP, cuja Estação Agroclimatológica está localizada à jusante da cidade, na bacia hidrográfica do Córrego Jaboticabal. A deficiência e o excedente hídrico do solo foram calculados através do balanço hídrico, segundo Thornthwaite e Mather (1955).

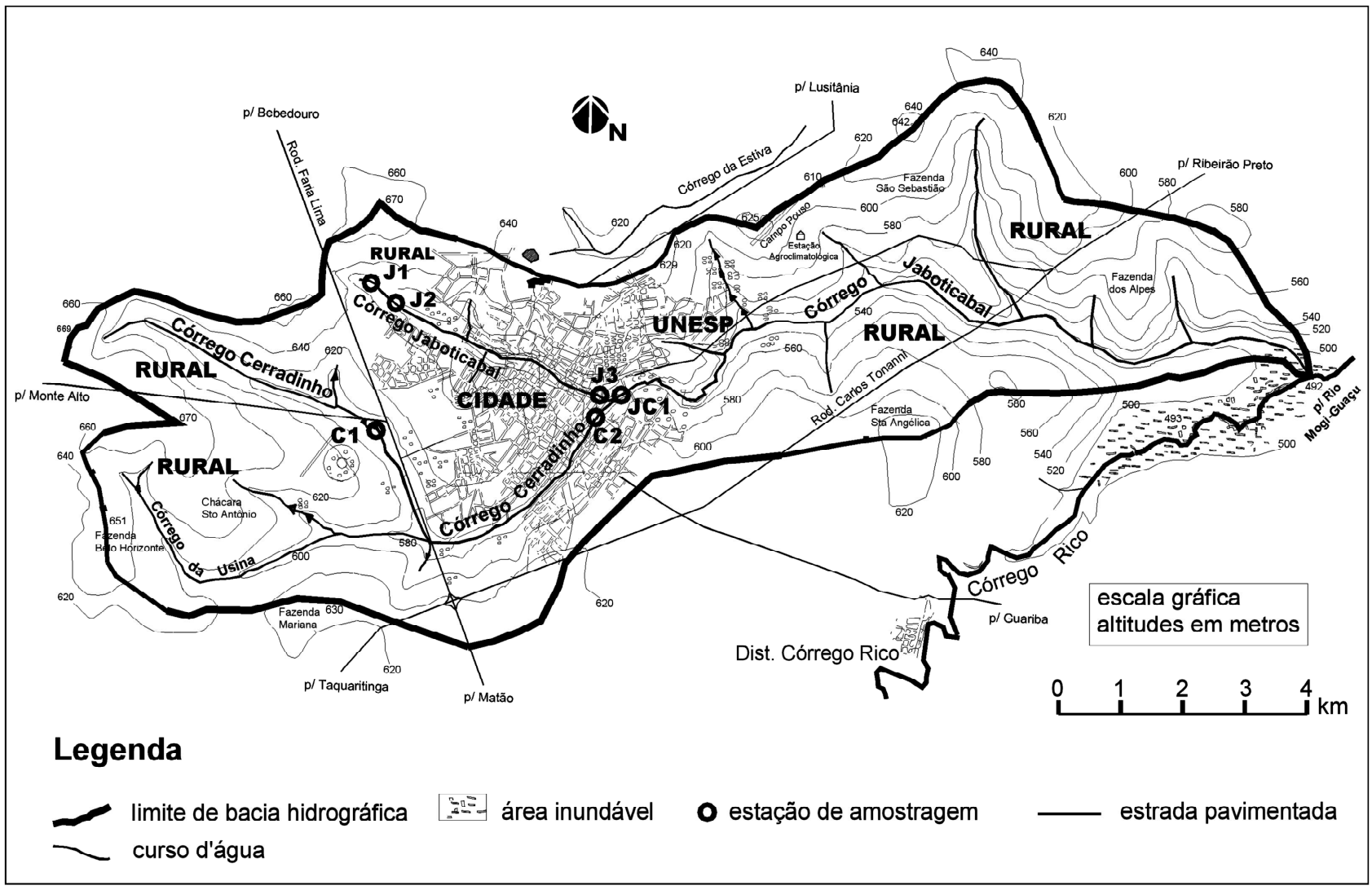

Figura 2. Estações de amostragem nos córregos Cerradinho e Jaboticabal, analisadas de maio/1999 a abril/2000. Fonte da escala: IGC, 1991. 
Tabela 2. Dados mensais de temperatura média do ar, precipitação e número de dias de chuva do município de Jaboticabal, SP.

\begin{tabular}{lccccc}
\hline Mês & $\begin{array}{c}\text { Temperatura* } \\
\text { média do ar }\left({ }^{\circ} \mathrm{C}\right)\end{array}$ & $\begin{array}{c}\text { Precipitação* } \\
(\mathrm{mm})\end{array}$ & $\begin{array}{c}\text { Déficit hídrico } \\
(\mathrm{mm})\end{array}$ & $\begin{array}{c}\text { Excedente hídrico } \\
(\mathrm{mm})\end{array}$ & Dias de chuva* \\
\hline Maio/99 & 18,6 & 28,6 & 0 & 0 & 2 \\
Junho/99 & 18,6 & 19,9 & 0 & 0 & 4 \\
Julho/99 & 20,3 & 2,0 & 5 & 0 & 3 \\
Agosto/99 & 20,8 & 0,0 & 70 & 0 & 0 \\
Setembro/99 & 22,7 & 78,8 & 11 & 0 & 7 \\
Outubro/99 & 23,5 & 67,7 & 0 & 0 & 8 \\
Novembro/99 & 23,0 & 82,5 & 0 & 0 & 11 \\
Dezembro/99 & 24,3 & 232,4 & 0 & 0 & 14 \\
Janeiro/00 & 24,2 & 276,1 & 0 & 152 & 17 \\
Fevereiro/00 & 24,0 & 241,7 & 0 & 138 & 17 \\
Março/00 & 23,6 & 106,9 & 0 & 0 & 4 \\
Abril/00 & 22,7 & 51,2 & 86 & 295 & 19 \\
No ano & 22,2 & $1.187,8$ & & \\
\hline
\end{tabular}

* Fonte: Estação Agrometeorológica FCAV/UNESP.

Além das análises dos valores obtidos mensalmente, analisou-se cada parâmetro calculando-se a média mensal (A) e a média anual (B) dos valores obtidos nas estações de amostragem, para se ter uma idéia das variações ao longo do ano, no trecho urbano da bacia.

$$
\text { Média Mensal }=(\mathrm{C} 1+\mathrm{C} 2+\mathrm{J} 1+\mathrm{J} 2+\mathrm{J} 3+\mathrm{JC} 1) / 6
$$

onde C1, ..., JC1 são as estações de amostragem.

$$
\begin{gathered}
\text { Média Anual }=(\mathrm{m}+\mathrm{j}+\mathrm{j}+\mathrm{a}+\mathrm{s}+\mathrm{o}+\mathrm{d}+\mathrm{j}+ \\
\mathrm{f}+\mathrm{m}+\mathrm{a}) / 11
\end{gathered}
$$

onde $m, j, \ldots, m$, a são os meses de amostragem.

A análise de variância dos dados foi realizada com a sub-rotina PROC GLM do software "SAS System for Windows Release", versão 6.12, sendo utilizado o teste F com a finalidade de comparar estimativas de variância, admitindo no máximo $5 \%$ de probabilidade de erro.

\section{RESULTADOS E DISCUSSÃO}

\section{Caracterização da qualidade hídrica dos córregos Cerradinho e Jaboticabal}

Vazão, temperatura e pH - Os valores de vazão, temperatura e $\mathrm{pH}$ detectados nas estações de amostragem dos córregos Cerradinho e Jaboticabal, estão representados nas Figuras 3 e 4 .

As menores vazões dos córregos ocorreram de julho a outubro e as maiores de dezembro a março, coincidindo, respectivamente, com o período de deficiência e de excedente hídrico do solo (Tabela 2). No curso d'água, se não houver retirada de água, quanto maior a distância do local de medição em relação à nascente, maior será a área de drenagem constituindo em maior aporte de água (Christofoletti, 1974).

As menores temperaturas da água ocorreram no mês de junho, sendo que, a cada medição, aumentou até dezembro, estabilizou de janeiro a março e diminuiu de abril a maio, comportando-se semelhante à temperatura do ar (Tabela 2). A temperatura da água sofre influência da temperatura do ar, admitindo-se que variações na temperatura do ar implicam em variações na temperatura da água, com menor intensidade; seu aumento diminui a densidade e a tensão da película formada pelas moléculas de água na camada superficial de contato com o ar, onde ocorre a troca de calor (Palma-Silva, 1999).

A estação J1 apresentou menor amplitude térmica $\left(3,4^{\circ} \mathrm{C}\right)$ por ser praticamente o instante em que a água do Córrego Jaboticabal aflora à superfície, sofrendo menor influência da incidência dos raios solares e da temperatura do ar. No interior do solo a água apresenta temperatura mais constante, semelhante à temperatura deste.

Os menores valores de $\mathrm{pH}$ ocorreram sempre na estação J1, permanecendo entre 4,4 e 4,9, resultados semelhantes aos obtidos por Amaral (1992) e SAAEJ (2000). Os baixos valores de $\mathrm{pH}$ da água nesta estação fornecem indício da ausência de substâncias tamponadoras como bicarbonatos e carbonatos em solução; sua maior concentração de íons $\mathrm{H}^{+}$pode ser decorrente do tipo de solo proveniente da Formação Botucatu e da presença de ácidos minerais e orgânicos, dissolvidos do material de origem alóctone (adubos) e/ou autóctone. A cobertura vegetal original dessa região era cerrado e atualmente predomina a cana-de-açúcar.

Apesar da proximidade entre as estações $\mathrm{J} 1$ e J2, o pH na J2 se eleva rapidamente em relação a J1. A vazão relativa- 


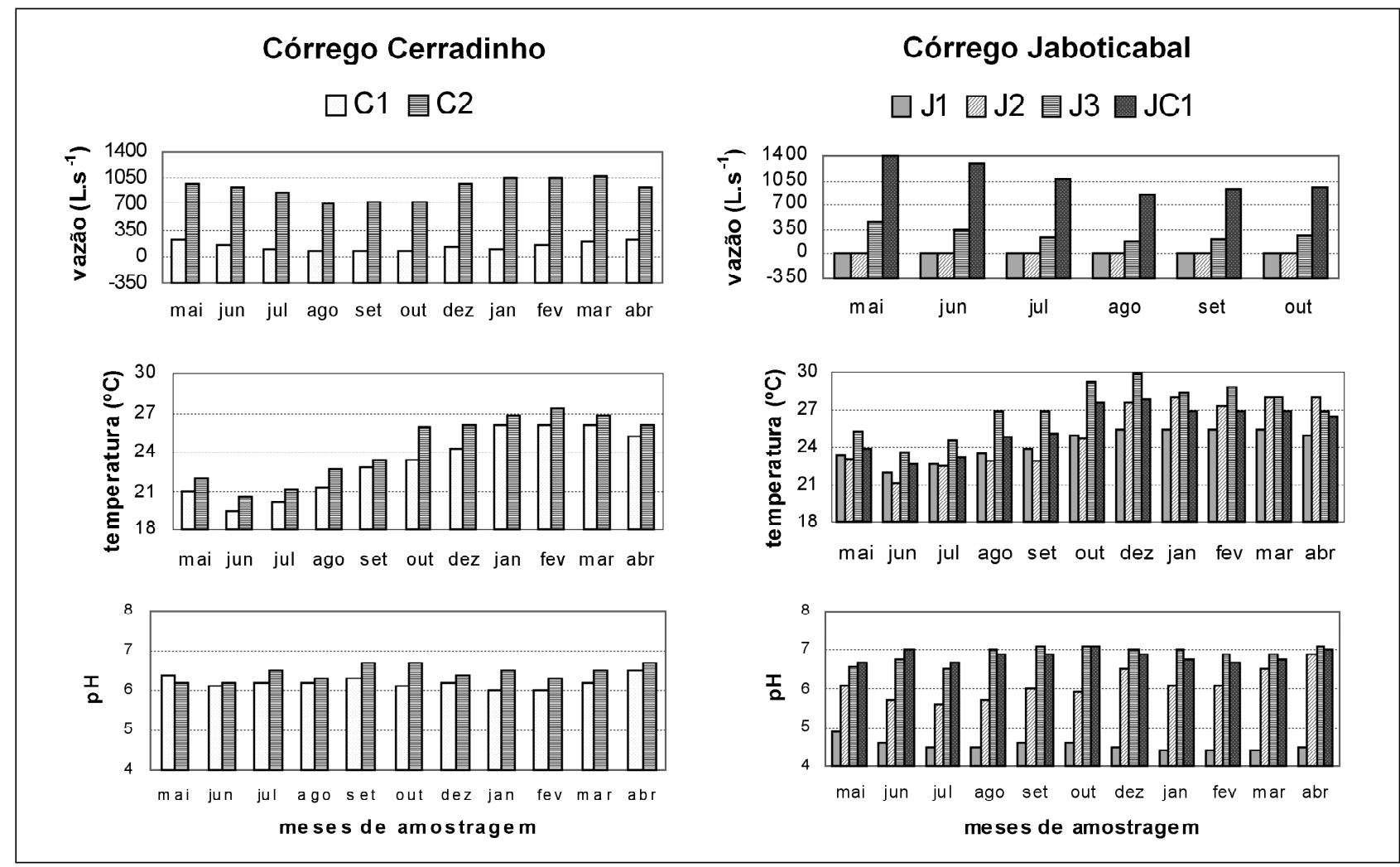

Figura 3. Vazão, temperatura e valor pH da água coletada nas estações dos córregos Cerradinho (C1; C2) e Jaboticabal (J1; J2; J3; JC1), de maio/1999 a abril/2000, Jaboticabal, SP.

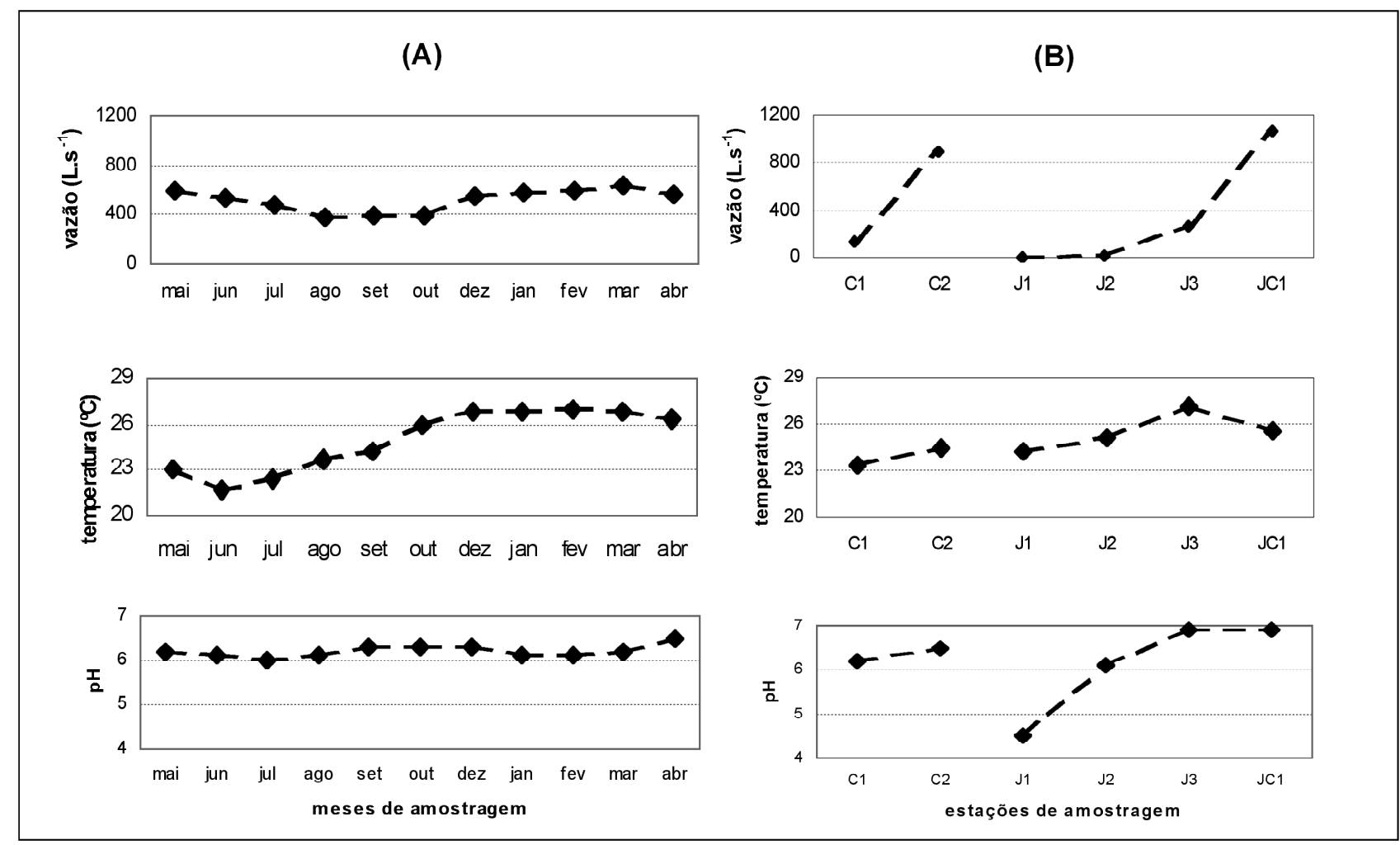

Figura 4. Valores médios da vazão, temperatura e pH da água em função do mês (A) e da estação (B) nos córregos Cerradinho (C1; C2) e Jaboticabal (J1; J2; J3; JC1), de maio/1999 a abril/2000, Jaboticabal, SP. 
mente baixa na estação $\mathrm{J} 2$ (média de $12 \mathrm{~L} \mathrm{~s}^{-1}$ ) pode estar permitindo que a água receba influência de substâncias tamponadoras, mesmo que em pequenas quantidades, originárias de atividades em chácaras (criações e residências) e de início da área urbanizada.

$\mathrm{Na}$ região de confluência dos córregos, na estação C2 do Córrego Cerradinho, sempre a vazão foi maior $(2$ a 4 vezes) e a temperatura e o $\mathrm{pH}$ foram menores que na $\mathrm{J} 3$ do Córrego Jaboticabal. A menor temperatura da água na estação C2 pode ser em função desse córrego estar canalizado e menos poluído, além de apresentar um curso mais definido e uma maior altura média de lamina d'água.

$\mathrm{Na}$ Figura 4a e na Tabela 3, as médias mensais dos valores obtidos nas estações de coleta, inferem que a época do ano influenciou nos valores de vazão e temperatura da água, os quais permaneceram por um maior período, próximos dos valores máximos, respectivamente de $635 \mathrm{~L} . \mathrm{s}^{-1}$ e $26,98^{\circ} \mathrm{C}$, do que dos mínimos, respectivamen-

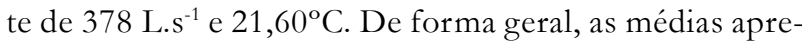
sentaram variabilidades maiores na vazão e na temperatura e menores no $\mathrm{pH}$.

Em relação às estações de amostragem (Figura 4b e Tabela 4), tanto a vazão quanto a temperatura e o $\mathrm{pH}$ na água apresentaram variabilidade, aumentando seus valores da nascente à confluência de suas águas. Ao receber as águas do Córrego Cerradinho, o Córrego Jaboticabal na estação JC1 apresentou redução nos valores de temperatura e pH, permanecendo semelhantes aos valores obtidos por Palhares et al. (2000) em águas à jusante dessa estação e por Amaral (1992) em águas do Córrego Rico.

DQO, $\mathbf{N}_{\text {total }}$ e $\mathbf{P}_{\text {total }}$ - Os valores de DQO, $\mathrm{N}_{\text {total }}$ e $\mathrm{P}_{\text {total }}$ nas estações de amostragem dos córregos Cerradinho e Jaboticabal, estão representados nas Figuras 5 e 6 . Praticamente os menores valores mensais de DQO e de $\mathrm{P}_{\text {total }}$, ocorreram nas estações à montante da cidade $(\mathrm{J} 1 \mathrm{e} \mathrm{C} 1)$, inclusive sendo encontrados valores traços em vários meses.

Os valores de $\mathrm{P}_{\text {total }}$ encontrados ficaram entre $0 \mathrm{e}$ $243 \mu \mathrm{g} . \mathrm{L}^{-1}$, sendo que em rios não influenciados por despejos, normalmente o $P_{\text {total }}$ é encontrado em concentrações que variam de 0,1 a $87 \mu$ g.L. $L^{-1}$ (CETESB, 1995).

$\mathrm{O}$ fato de nas estações $\mathrm{C} 2$, J2, J3 e JC1 terem sido encontrados valores de $\mathrm{P}_{\text {total }}$ superiores a $87 \mu \mathrm{g} . \mathrm{L}^{-1}$, demonstra a existência de despejos pois estão em região urbana, existindo atividades que utilizam o fosfato, o qual pode ser adicionado à água para prevenir formação de incrustações, inibir corrosão e melhorar a eficiência da ação de lavagem e limpeza (CETESB, 1995).

Os valores de $\mathrm{N}_{\text {total }}$ encontrados ficaram entre $2,2 \mathrm{e}$ $10,4 \mathrm{mg} . \mathrm{L}^{-1}$, sendo que em rios não influenciados pelo excesso de insumos orgânicos, a concentração de $\mathrm{N}_{\text {total }}$ varia de 0,1 a 0,5 mg.L ${ }^{-1}$ (CETESB, 1995).

$\mathrm{Na}$ estação J1 os valores de $\mathrm{N}_{\text {total }}$ variaram de 2,2 a 7,0 mg. $\mathrm{L}^{-1}$. Por ser praticamente o instante em que a água do
Tabela 3. Médias mensais de vazão, temperatura e $\mathrm{pH}$ da água nas estações dos córregos Cerradinho e Jaboticabal.

\begin{tabular}{lccc}
\hline Mês & $\begin{array}{c}\text { Vazão } \\
\text { L.s }{ }^{-1}\end{array}$ & $\begin{array}{c}\text { Temperatura* } \\
\left({ }^{\circ} \mathrm{C}\right)\end{array}$ & $\mathrm{pH} *$ \\
\hline Maio & 588 & $23,08 \mathrm{bcd}$ & $6,15 \mathrm{ab}$ \\
Junho & 542 & $21,60 \mathrm{~d}$ & $6,07 \mathrm{ab}$ \\
Julho & 471 & $22,38 \mathrm{~cd}$ & $6,00 \mathrm{~b}$ \\
Agosto & 378 & $23,65 \mathrm{bc}$ & $6,10 \mathrm{ab}$ \\
Setembro & 394 & $24,15 \mathrm{~b}$ & $6,27 \mathrm{ab}$ \\
Outubro & 384 & $25,95 \mathrm{a}$ & $6,25 \mathrm{ab}$ \\
Dezembro & 547 & $26,78 \mathrm{a}$ & $6,25 \mathrm{ab}$ \\
Janeiro & 573 & $26,88 \mathrm{a}$ & $6,13 \mathrm{ab}$ \\
Fevereiro & 593 & $26,98 \mathrm{a}$ & $6,07 \mathrm{ab}$ \\
Março & 635 & $26,85 \mathrm{a}$ & $6,22 \mathrm{ab}$ \\
Abril & 568 & $26,28 \mathrm{a}$ & $6,45 \mathrm{a}$ \\
Pr $>$ F & ----- & 0,0001 & 0,0233 \\
dms & ----- & 1,6455 & 0,3925 \\
\hline
\end{tabular}

* Valores com mesma letra não diferem entre si pelo teste T a 5\%.

Tabela 4. Médias anuais de vazão, temperatura e pH da água nas estações dos córregos Cerradinho e Jaboticabal.

\begin{tabular}{cccl}
\hline Estação & $\begin{array}{c}\text { Vazão } \\
\text { L.s }^{-1}\end{array}$ & $\begin{array}{c}\text { Temperatura } * \\
\left({ }^{\circ} \mathrm{C}\right)\end{array}$ & $\mathrm{pH}^{*}$ \\
\hline $\mathrm{C} 1$ & 133 & $23,27 \mathrm{~d}$ & $6,20 \mathrm{bc}$ \\
$\mathrm{C} 2$ & 898 & $24,45 \mathrm{c}$ & $6,45 \mathrm{~b}$ \\
$\mathrm{~J} 1$ & $<1$ & $24,23 \mathrm{~cd}$ & $4,54 \mathrm{~d}$ \\
$\mathrm{~J} 2$ & 12 & $25,09 \mathrm{bc}$ & $6,10 \mathrm{c}$ \\
$\mathrm{J} 3$ & 268 & $27,10 \mathrm{a}$ & $6,91 \mathrm{a}$ \\
$\mathrm{JC} 1$ & 1.073 & $25,65 \mathrm{~b}$ & $6,86 \mathrm{a}$ \\
$\mathrm{Pr}>\mathrm{F}$ & ------ & 0,0001 & 0,0001 \\
$\mathrm{dms}$ & ----- & 1,068 & 0,2548 \\
\hline
\end{tabular}

* Valores com mesma letra não diferem entre si pelo teste $\mathrm{T}$ a $5 \%$.

Córrego Jaboticabal aflora à superfície, pode ser que parte dessa contribuição tenha origem no próprio manancial de abastecimento, em cuja região existe lavoura de cana de açúcar e foi feita a recomposição de uma mata onde foi utilizada adubação nitrogenada.

$\mathrm{Na}$ região de confluência dos córregos, em diversos meses os valores de $\mathrm{N}_{\text {total }}$ na estação JC1 foram maiores que em J3 e C2. Esses teores inferem sobre a existência de fonte poluidora rica em nitrogênio próxima a estação JC1.

A partir de agosto, as estações J3 e JC1 apresentaram redução na $\mathrm{DQO}$ e no $\mathrm{P}_{\text {total }}$ mantendo os valores próximos aos da C2. Essa redução pode ter ocorrido em função da coleta de esgoto nas margens do Córrego Jaboticabal em área urbana, reduzindo o teor de compostos orgânicos em suas águas.

No mês de abril ocorreu menor número de dias chuvosos em relação ao mês anterior (Tabela 2), podendo ter exercido influência para a elevação dos teores de DQO, $\mathrm{P}_{\text {total }}$ e $\mathrm{N}_{\text {total }}$ nas águas dos córregos estudados. Principalmente na 


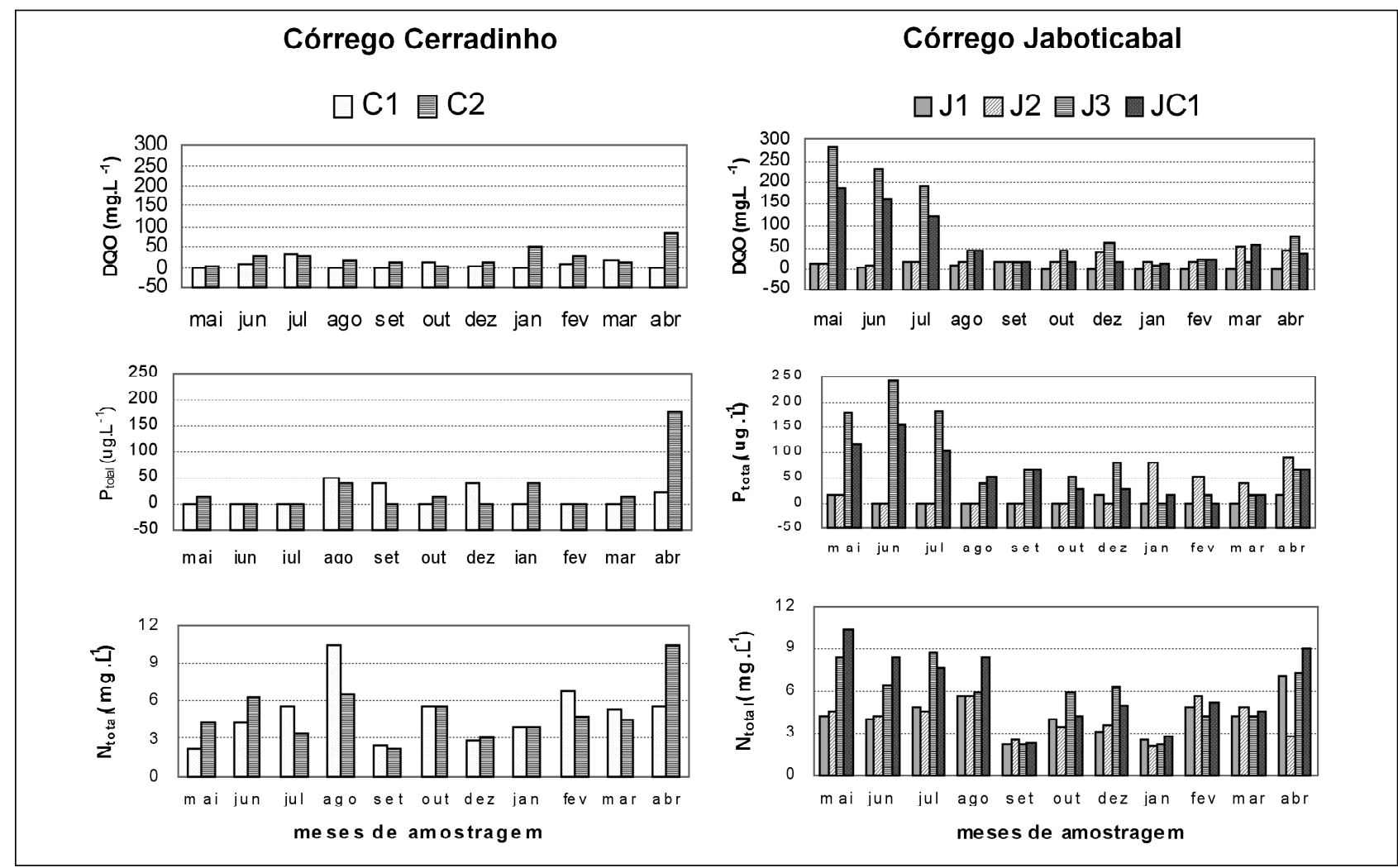

Figura 5. Teor de DQO, $P_{\text {total }}$ e $\mathbf{N}_{\text {total }}$ na água coletada nas estações dos córregos Cerradinho (C1; C2) e Jaboticabal (J1; J2; J3; JC1), de maio/1999 à abrill2000, Jaboticabal, SP.

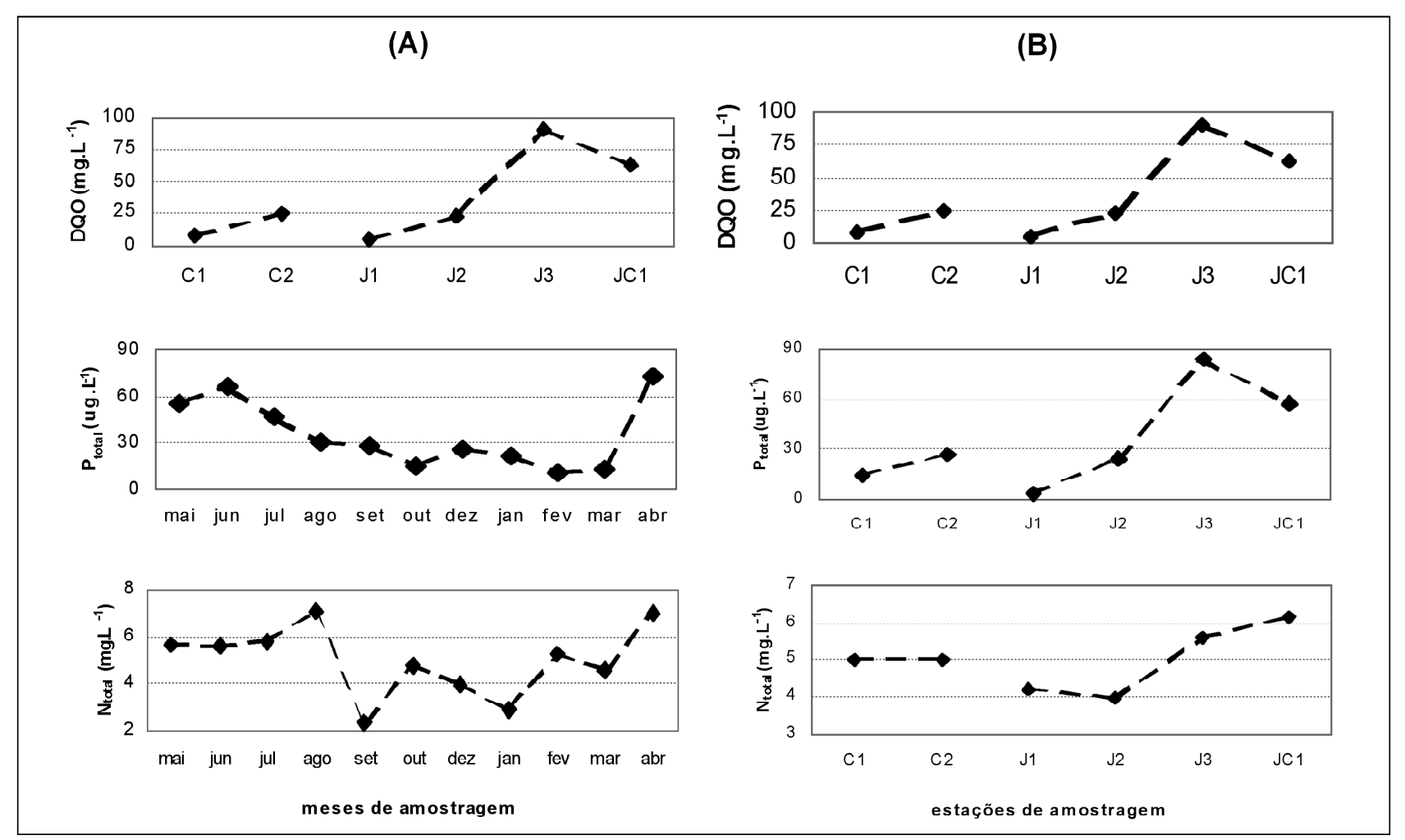

Figura 6. Valores médios da DQO, $P_{\text {total }}$ e $N_{\text {total }}$ da água em função do mês (A) e da estação (B) nos córregos Cerradinho (C1;C2) e Jaboticabal (J1;J2;J3;JC1), maio/1999 a abril/2000, Jaboticabal, SP. 
estação C2 do Córrego Cerradinho, estes altos teores podem ainda ter sido provocados por despejos ocasionais pois existem estabelecimentos comerciais prestadores de serviços próximos a esta estação.

Na Figura 6a e na Tabela 5, as médias mensais dos valores obtidos nas estações de coleta, inferem que a época do ano influenciou nos valores de DQO e $\mathrm{P}_{\text {total }}$.

Em relação às estações de amostragem (Figura 6b e Tabela 6), das nascentes a confluência dos córregos a tendência foi de aumento da DQO, $\mathrm{P}_{\text {total }}$ e $\mathrm{N}_{\text {total }}$. Esse aumento ocorreu principalmente no período de maio a julho/1999 (Tabela 5), quando os coletores de esgoto no Córrego Jaboticabal ainda não estavam em funcionamento, permitindo a presença de grande quantidade de compostos orgânicos em suas águas. Essa tendência de aumento também foi observada no mês de abril, o que leva a inferir quanto à existência de entrada de efluentes poluentes urbanos, mesmo com a presença dos interceptores de esgoto.

Geralmente, os menores valores dos parâmetros analisados ocorreram nas estações (ordem crescente): J1, C1, J2, C2, JC1 e J3. A melhor qualidade da água na estação J1 é explicada pela ausência de ação antrópica direta; na C1 a poluição é devido à ação de agentes rurais como práticas agrícolas, criação de animais e áreas de lazer; no J2 e C2 a presença de resíduos urbanos aumenta a poluição porém a contribuição de esgoto orgânico é baixa pela presença dos coletores às margens dos córregos; na JC1 e J3 a emissão de esgoto orgânico nas águas do Córrego Jaboticabal principalmente de maio a julho, foi o responsável pela elevação dos valores médios dos parâmetros.

Os resultados mostram que as variáveis básicas são eficazes na identificação e no monitoramento de corpos d'água alterados por descargas de esgotos orgânicos. Essa análise é coerente com resultados obtidos por Camargo et al. (1995) e Palma-Silva (1999) ao avaliarem o impacto das descargas de esgotos orgânicos em corpos d'água do município de Rio Claro, SP.

Estes resultados mostram afinal que os interceptores de esgoto contribuíram para a melhoria da qualidade da água dos córregos Cerradinho e Jaboticabal, mas não o suficiente para considerá-los despoluídos, estando, ainda, distantes das condições ideais de abastecimento urbano ou de uso mais exigente.

\section{Enquadramento das águas do córrego Jaboticabal}

A Resolução CONAMA nº20/86 (CONAMA, 1986) estabelece, para os cursos d' água brasileiros, limites de qualidade hídrica a serem respeitados e colocados em Classes, sendo mais restritivos quanto mais nobre for o uso pretendido.
Tabela 5. Médias mensais de DQO, $P_{\text {total }}$ e $N_{\text {total }}$ da água nas estações dos córregos Cerradinho e Jaboticabal.

\begin{tabular}{|c|c|c|c|}
\hline Mês & $\begin{array}{l}\text { DQO } \\
\text { mg.L-1 }\end{array}$ & $\begin{array}{c}P_{\text {total }} \\
\mu \mathrm{g} . \mathrm{L}^{-1}\end{array}$ & $\begin{array}{l}\mathrm{N}_{\text {total }}{ }^{*} \\
\mathrm{mg} \cdot \mathrm{L}^{-1}\end{array}$ \\
\hline Maio & 83,8 & 55,5 & $5,65 \mathrm{ab}$ \\
\hline Junho & 73,3 & 66,1 & $5,55 \mathrm{ab}$ \\
\hline Julho & 69,5 & 46,9 & $5,77 \mathrm{ab}$ \\
\hline Agosto & 21,5 & 29,9 & $7,07 \mathrm{a}$ \\
\hline Setembro & 13,8 & 27,7 & $2,31 \mathrm{c}$ \\
\hline Outubro & 14,8 & 14,9 & 4,77 abc \\
\hline Dezembro & 21,5 & 25,6 & $3,97 \mathrm{bc}$ \\
\hline Janeiro & 13,0 & 21,3 & $2,88 \mathrm{bc}$ \\
\hline Fevereiro & 15,7 & 10,7 & $5,22 \mathrm{abc}$ \\
\hline Março & 25,3 & 12,8 & $4,58 \mathrm{abc}$ \\
\hline Abril & 40,2 & 72,5 & $7,02 \mathrm{a}$ \\
\hline $\operatorname{Pr}>F$ & ------ & ------ & 0,0001 \\
\hline $\mathrm{dms}$ & ------ & ------ & 3,0468 \\
\hline
\end{tabular}

* Valores com mesma letra não diferem entre si pelo teste T a $5 \%$.

Tabela 6. Médias anuais de DQO, $P_{\text {total }}$ e $N_{\text {total }}$ da água nas estações dos córregos Cerradinho e Jaboticabal.

\begin{tabular}{|c|c|c|c|}
\hline Estação & $\begin{array}{l}\text { DQO* } \\
\text { mg.L-1 }\end{array}$ & $\begin{array}{l}\mathrm{P}_{\text {total }} * \\
\mu \mathrm{g} . \mathrm{L}^{-1}\end{array}$ & $\begin{array}{l}\mathrm{N}_{\text {total }}{ }^{*} \\
\text { mg.L }{ }^{-1}\end{array}$ \\
\hline $\mathrm{C} 1$ & $7,6 \mathrm{~b}$ & $13,9 \mathrm{~b}$ & $4,98 \mathrm{ab}$ \\
\hline $\mathrm{C} 2$ & $25,3 \mathrm{~b}$ & $26,8 \mathrm{ab}$ & $4,99 \mathrm{ab}$ \\
\hline $\mathrm{J} 1$ & $5,4 \mathrm{~b}$ & $3,5 \mathrm{~b}$ & $4,20 \mathrm{ab}$ \\
\hline $\mathrm{J} 2$ & $22,9 \mathrm{~b}$ & $24,5 \mathrm{~b}$ & $3,95 \mathrm{~b}$ \\
\hline $\mathrm{J} 3$ & $90,3 \mathrm{a}$ & 83,8 a & $5,59 \mathrm{ab}$ \\
\hline JC1 & $62,6 \mathrm{ab}$ & $57,0 \mathrm{ab}$ & 6,16 a \\
\hline $\operatorname{Pr}>F$ & 0,0002 & 0,0013 & 0,0167 \\
\hline $\mathrm{dms}$ & 57,618 & 57,533 & 1,977 \\
\hline
\end{tabular}

* Valores com mesma letra não diferem entre si pelo teste T a 5\%.

Segundo CETESB (1994) as águas do Córrego Jaboticabal são de Classe 4, podendo ser destinadas à navegação, à harmonia paisagística e a usos menos exigentes.

$\mathrm{Na}$ Tabela 7, identifica-se o enquadramento das águas nas estações de amostragem em função dos parâmetros de qualidade determinados por essa Resolução.

Nas estações $\mathrm{J} 1$ e J2 foram encontrados valores de $\mathrm{pH}$ abaixo de 6,0, portanto fora do limite determinado pela Resolução CONAMA 20/86 para os rios de Classe 1 a 4 (pH entre 6,0 e 9,0); nas demais estações os valores permaneceram entre 6,0 e 7,1 .

No parâmetro $\mathrm{P}_{\text {total }}$, a estação J1 foi a única cujos teores em todos os meses ficaram abaixo do limite de $25 \mu \mathrm{g} . \mathrm{L}^{-1}$ determinado para as Classes de 1 a 3.

$\mathrm{Na}$ Tabela 8 são apresentados os resultados dos parâmetros analisados de agosto/1999 a abril/2000 na estação JC1 do Córrego Jaboticabal, período este em que já estava em funcionamento o sistema de coleta de esgoto através de interceptores nas margens dos córregos Cerradinho 
e Jaboticabal em área urbana. Nessa mesma tabela são apresentados os valores obtidos pela CETESB (1994) no curso médio superior do Rio Mogi-Guaçu nos pontos de amostragem MG2190 e MG2280, respectivamente à montante e à jusante da foz de seu afluente Córrego Rico, e os limites de qualidade da água impostos à Classe 2 pela Resolução CONAMA 20/86.

Em relação ao Rio Mogi-Guaçu, a estação JC1 apresentou valores intermediários de $\mathrm{pH}$, semelhantes de temperatura, maiores de $\mathrm{N}_{\text {total }}$, ocasionais maiores de DQO e ocasionais menores de $\mathrm{P}_{\text {total }}$. Esses maiores valores de $\mathrm{P}_{\text {total }}$ no Rio Mogi-Guaçu podem ser pelo fato desse rio receber efluentes da agroindústria canavieira, a qual pode estar ocasionalmente liberando resíduos ricos em fósforo como o material de lavagem e limpeza de seus equipamentos industriais.

Como a DQO e o Ntotal são parâmetros que demonstram a presença de despejos na água, infere-se que a qualidade de água do Córrego Jaboticabal na JC1 é pior que a do Rio Mogi-Guaçu.

\section{Proposta de ações mitigadoras}

Considerando que o Plano Diretor do Município de Jaboticabal (Jaboticabal, 2000), recomenda em suas diretrizes a canalização, recuperação e tratamento paisagístico dos córregos da zona urbana; a expansão do município associado à existência de sistemas de abastecimento de água e de afastamento do esgoto; a recuperação dos recursos naturais degradados por ação do homem ou da natureza; e a melhoria da qualidade ambiental através do controle da poluição da água, do solo e visual, os resultados obtidos nessa pesquisa permitem propor:

- Implantar um plano de monitoramento contínuo da qualidade da água dos cursos d'água;

- Implantar estações hidrométricas para conhecimento adequado do regime de vazões dos córregos;

- Executar o tratamento do esgoto domiciliar e industrial, impedindo seu despejo "in natura" nos cursos d'água;

- Impedir o lançamento de esgoto clandestino humano ou animal nos cursos d'água;

- Melhorar o sistema de limpeza urbana, reduzindo a ação impactante do escoamento superficial, seja de lixos domiciliares ou de resíduos sólidos de diversas origens;

- Fiscalizar efetivamente os estabelecimentos que apresentam uso intenso de produtos químicos e que tem acesso direto aos córregos;

- Fiscalizar as práticas rurais, recomendando práticas conservacionistas do solo, controle no uso de adubação e de defensivos agrícolas e no manejo de criações;
Tabela 7. Classificação dos córregos Cerradinho e Jaboticabal, nas estações de amostragem, em função da Resolução CONAMA 20/86.

Estação de amostragem Classe em função do parâmetro $\mathrm{pH} \quad \mathrm{P}_{\text {total }}$

\begin{tabular}{ccc} 
& $\mathrm{pH}$ & $\mathrm{P}_{\text {total }}$ \\
\hline $\mathrm{C} 1$ & 1 a 4 & $*$ \\
$\mathrm{C} 2$ & 1 a 4 & $*$ \\
$\mathrm{~J} 1$ & $*$ & 1 a 3 \\
$\mathrm{~J} 2$ & $*$ & $*$ \\
$\mathrm{~J} 3$ & 1 a 4 & $*$ \\
$\mathrm{JC} 1$ & 1 a 4 & $*$ \\
\hline
\end{tabular}

* Valores fora das concentrações estabelecidas para as classes de 1 a 4.

Tabela 8. Parâmetros com valores limites Classe 2 e valores no córrego Jaboticabal (estação JC1) e no rio Mogi-Guaçu (pontos MG2190 e MG2280). Fonte. CETESB, 1994.

\begin{tabular}{|c|c|c|c|}
\hline Parâmetro & $\begin{array}{l}\text { Limite* } \\
\text { Classe } 2\end{array}$ & $\begin{array}{c}\text { Córrego } \\
\text { Jaboticabal } \\
\text { JC1 }\end{array}$ & $\begin{array}{c}\text { Rio Mogi-Guaçu } \\
\text { MG2190 e } \\
\text { MG2280* }\end{array}$ \\
\hline $\begin{array}{l}\text { Temperatura da } \\
\text { água }\left({ }^{\circ} \mathrm{C}\right)\end{array}$ & ----- & 24,8 a 27,8 & 24 a 27 \\
\hline $\mathrm{pH}$ & 6 a 9 & 6,7 a 7,1 & 6,2 a 8,8 \\
\hline $\mathrm{N}_{\text {total }}\left(\mathrm{mg} \cdot \mathrm{L}^{-1}\right)$ & ----- & 2,3 a 9,0 & 0,77 a 1,79 \\
\hline$P_{\text {total }}\left(\mathrm{mg} \cdot \mathrm{L}^{-1}\right)$ & 0,025 & 0 a 0,064 & $<0,002$ a 0,178 \\
\hline DQO (mg.L-1 $)$ & ---- & 11 a 57 & $<14$ a 22 \\
\hline
\end{tabular}

- Cumprir a legislação referente à proteção de mananciais, reflorestando as nascentes e implantando matas ciliares nos córregos;

- Recuperar paisagisticamente os cursos d'água, suplementando atrativos que valorizem seu potencial hídrico para lazer e que reduzam a poluição visual;

- Fomentar práticas que facilitem a infiltração da água no solo em áreas públicas e particulares reduzindo os efeitos do escoamento superficial e permitindo o abastecimento regular dos mananciais e lençol freático;

- Implantar um programa de educação ambiental que resgate o valor histórico dos cursos d'água urbanos e que desperte na população sua participação como agente responsável pela recuperação da qualidade ambiental através da incorporação dos princípios de desenvolvimento sustentável das políticas públicas;

- Implantar programa de irrigação agrícola, aproveitando o solo como depurador hídrico e a água residuária como fonte hídrica e de nutrientes para as plantas;

- Fomentar a parceria entre a Prefeitura de Jaboticabal e a UNESP, no desenvolvimento de pesquisas de Interesse mútuo, valendo-se da importância e da posição estratégica da área de domínio dessas instituições em relação à bacia hidrográfica do Córrego Jaboticabal. 


\section{CONCLUSÃO}

Os resultados obtidos nesta pesquisa permitem concluir que:

- O monitoramento da qualidade hídrica dos córregos Cerradinho e Jaboticabal, detectou a intensidade com que poluentes estão presentes nos pontos de amostragem.

- Tanto no Córrego Cerradinho quanto no Córrego Jaboticabal em área urbana, houve aumento da poluição hídrica das nascentes à foz nos parâmetros de DQO, $\mathrm{P}_{\text {total }}$ e $\mathrm{N}_{\text {total }}$, sendo identificada variação em função do tempo na vazão, na temperatura, na DQO e no $\mathrm{P}_{\text {total }}$.

- A implantação dos interceptores de esgoto não foi suficiente para despoluir as águas dos Córregos Cerradinho e Jaboticabal, apesar de diminuir sua intensidade.

- Pesquisas devem ser conduzidas de forma a contemplar maior período de análise.

- É necessário desenvolver um plano integrado de manejo hídrico na bacia hidrográfica do Córrego Jaboticabal minimizando ou até eliminando sua contribuição negativa à comunidade local e às águas localizadas à jusante da área urbana.

\section{AGRADECIMENTOS}

Agradecimentos a Euripedes DeOliveira, Master in Arts, Urban Planner/Regional and International Development, UCLA/USA (DeOliveira Associates; POBox 4741, Valley Village, CA, 91617USA) pela colaboração no Abstract.

\section{REFERÊNCIAS}

AMARAL, L. A. do (1992). Influência da precipitação pluviométrica nas características bacteriológicas, físicas e químicas da água de diferentes mananciais de abastecimento da cidade de Jaboticabal, SP. 113 f. Tese (Doutorado em Saúde Pública). Faculdade de Saúde Pública, Universidade de São Paulo, São Paulo.

AMAral, L. A. do (2000). A qualidade e um mito. Pesquisa FAPESP, São Paulo, n. 50, p. 28-31 (encarte especial).

APHA (1995). American Public Health Association - Standard methods for examination of water and wastewater. 19th. ed. Washington: EPS Group, p. 1 1-9.68.

AZEVEDO NETO, J. M. de e ALVAREZ, G. A. (1982). Manual de bidráulica. 7. ed. São Paulo: Edgard Blücher, vol. 2, p. 333-500.

CAMARGO, A. F. M.; BINI, L. M. e SCHIAVETTI, A. (1995). Avaliação dos impactos provocados pelas descargas de esgotos orgânicos em alguns corpos d'água do município de Rio Claro. Oecologia Brasiliensis, Rio de Janeiro, vol. 2, p. 395-406.

CAVALCANTI, M. S. D. (1998). Esgotamento sanitário no município de Teresópolis, RJ. In: Reunião da Sociedade Brasileira para o Progresso da Ciência (SBPC), 50, Natal. Anais. Natal: São Paulo Ind. Gráf. e Edit., p. 1135.

CETESB (1994). Companhia de Tecnologia de Saneamento Ambiental - Relatório de qualidade das águas interiores do Estado de São Paulo, 1993. São Paulo, 225 p.

CETESB (1995). Companhia de Tecnologia de Saneamento Ambiental - Legislação: água para consumo humano, potabilidade, fluoretação. São Paulo. 67 p. (Série Documentos/ Secretaria do Meio Ambiente).

CHISTOFOLETTI, A. (1974). Geomorfologia. São Paulo: Edgard Blücher. Ed. da Universidade de São Paulo, 149 p.

CONAMA (1986). Conselho Nacional do Meio Ambiente Resolução CONAMA n. 20: classificação das águas do território nacional. Brasília: Imprensa oficial, p. 43-53.

FERNANDES, M. C. (1998). Retrato sócio-ambiental de uma cidade de porte médio do Rio Grande do Norte. In: Reunião da Sociedade Brasileira para o Progresso da Ciência (SBPC), 50, Natal. Anais. Natal: São Paulo Ind. Gráf. e Edit., p. 1137.

GRECCO, D. (1998). O planeta está secando. Globo Ciência, Rio de Janeiro, vol. 8, n. 85, p. 54-60.

IBGE (2000). Instituto Brasileiro de Geografia e Estatística - Censo Demográfico São Paulo 2000: dados preliminares. Rio de Janeiro.

IGC (1991). Instituto Geográfico e Cartográfico - Coordenadoria de Planejamento Regional. Plano Cartográfico do Estado de São Paulo: 1991. São Paulo: Secretaria de Planejamento e Gestão.

JABOTICABAL (2000). Ante-Projeto de Lei Complementar: revisão do Plano Diretor de Jaboticabal. Jaboticabal, 173 p.

MAIA, J. S. da S. (1998). Análise das características da água e dos impactos antrópicos na bacia hidrográfica: uma estratégia eficiente para a prática da educação ambiental em instituições de ensino. In: Reunião da Sociedade Brasileira para o Progresso da Ciência (SBPC), 50. Natal. Anais. Natal: São Paulo Ind. Gráf. e Edit., p. 640.

MALAVOLTA, E.; VITTI, G. C. \& OLIVEIRA, S. A. de. (1989). Avaliação do estado nutricional das plantas. princípios e aplicações. Piracicaba: Associação Brasileira para Pesquisa da Potassa e do Fosfato, 201 p.

MARGALEF, R. (1983). Limnologia. Barcelona: Ômega. 1100 p.

MATHEUS, C. E.; MORAES, A. J. de; TUNDISI, T. M. \& TUNDISI, J. G. (1995). Manual de análises limnológicas. São Carlos: Centro de Recursos Hídricos e Ecologia Aplicada, USP. 62 p.

PÁDUA, H. B. de. (1997). Variáveis físicas, químicas e biológicas para caracterização das águas em sistemas abertos. In: Martos, H. L.; Maia, N. B. (Coord.). Indicadores ambientais. Sorocaba: Bandeirantes Indústria Gráfica, p. 89-98.

PALHARES, J. C. P.; SCANDOLERA, A. J.; LUCAS Jr, J. e COSTA, A. J. da. (2000). Monitoramento da qualidade da água do Córrego Jaboticabal através de parâmetros químicos. In: Workshop de Integração de Informações da Bacia 
Hidrográfica do Rio Mogi Guaçu, 3. Porto Ferreira. Anais. Porto Ferreira: a Prefeitura 2000, p. 43-44.

PALMA-SILVA, G. M. (1999). Diagnóstico ambiental, qualidade da água e indice de depuração do Rio Corumbataí, SP. 155 f. Dissertação (Mestrado em Manejo Integrado de Recursos) Centro de Estudos Ambientais, Universidade Estadual Paulista, Rio Claro.

SAAEJ - SERVIÇO AUTÔNOMO DE ÁGUA E ESGOTO DE JABOTICABAL (2000). Relatórios técnicos. Jaboticabal: a Autarquia.

SANTOS, S. S. M. dos. (1993). Saneamento básico. In: IBGE. Instituto Brasileiro de Geografia e Estatística. Recursos naturais e meio ambiente: uma visão do Brasil. Rio de Janeiro, cap. 9, p. 101-112.

SIPAUBA-TAVARES, L. H. (1998). Influência do "óxido de cálcio propeixe" na qualidade da água e de peixes criados em viveiros de piscicultura: relatório parcial do projeto. Jaboticabal, $46 \mathrm{p}$.

THORNTHWAITE, C. W. \& MATHER, J. R. (1955). The water balance. Centerton: Pubs. Clim. Drexel Inst. Technol., 104 p.

VALERI, S. V. e MENEZES, J. M. T. (2000). Biodiversidade e potencialidade de sistemas agroflorestais na região de Jaboticabal, Estado de São Paulo. In: Congresso Brasileiro de Sistemas Agroflorestais: Manejando a Biodiversidade e Compondo a Paisagem Rural, 3., Manaus. Anais. Manaus: Imprensa Universitária, p. 63-65.

VITTA, A. (1999). História do saneamento básico de Jaboticabal. Jaboticabal: Fábrica da Palavra. 93 p.

\section{Monitoring Water Quality and the Efficiency of Sewage System Interceptors Within the Urban Perimeter of the Jaboticabal Stream Watershed}

\section{ABSTRACT}

Water samples were collected before and after the confluence of the Cerradinho and Jaboticabal streams, and analyzed for the purpose of evaluating the effectiveness of the existing sewage system as an interceptor for sewage discharged into both streams. The flow, temperature, $p H$, chemical oxygen demand, total phosphorus and total nitrogen parameters were analyzed monthly. From the results of the research it can be concluded that the levels of water pollution have increased within the urban perimeter of the Cerradinho and Jaboticabal streams and the outcome of the study suggests that the sewage system intercepting pollution discharge has not been sufficient to clean the waters of both streams, despite reducing the pollution. New studies are to be performed allocating more time for analysis. The development of an integrated plan to control the Jaboticabal stream watershed is recommended to minimize or even eradicate its negative impact on the local community within the urban and rural perimeters.

Key words: sewage systems interceptors; stream. 